\title{
El poder aeroespacial ya es un hecho
}

\section{José Tamame Camarero}

Arbor CLXXI, 674 (Febrero 2002), 217-229 pp.

Tras establecer los nuevos condicionantes que, a juicio del autor, marcan el nuevo escenario internacional, se determina la necesidad del empleo militar del espacio y del Poder Espacial como elementos fundamentales de la acción militar en el actual y venidero contexto estratégico mundial. Así, concluye que el Poder Espacial, su consecución y mantenimiento, constituye uno de los factores clave para la seguridad y defensa, no sólo de los intereses militares, sino también de los políticos y económicos de cualquier nación, y en particular de España.

A nivel general, constata el hecho de que el espacio ha perdido en los últimos años su carácter exclusivamente militar, sin dejar por ello de ser un factor esencial para la seguridad y para la defensa de los intereses de cualquier país.

En cuanto a la situación en Europa, se analiza en particular el área espacial de los países de la Unión, en la que se detecta la conveniencia de concretar y definir las necesidades para el futuro.

Para finalizar, y en lo que se refiere a la situación de España, considera la necesidad de consolidar el poder aeroespacial dentro del entorno de cooperación en Europa.

\section{Introducción}

Todos somos conscientes de que fue el temor mutuo soviético-estadounidense lo que dio lugar a la carrera espacial iniciada en los años cin- 
cuenta. Y es por esos años (1955), incluso antes de que la URSS pusiera en órbita los Sputnik (1957), cuando la Agencia Central de Inteligencia norteamericana (CIA) patrocina contratos con vistas a un Sistema Estratégico de Satélites, y la empresa Lockheed firma (1956) un compromiso para desarrollar el cohete-satélite AGENA.

La efectividad en cuanto a utilización de satélites y aviones en el campo de la observación va turnándose de forma alternativa entre los años sesenta y ochenta, y es a finales de los ochenta, principios de los noventa, cuando se tiende a pensar que lo ideal es una combinación de ambos.

Comenzaba a nacer un nuevo concepto. Hoy, una realidad consecuencia del actual escenario.

\section{¿Un nuevo escenario internacional?}

Por utópico que parezca, el escenario internacional es siempre nuevo, puesto que los cambios son constantes, ya sea en estructura, en dimensión o en intensidad.

En cualquier caso, aspectos como la mundialización y la globalización condicionan ese escenario. La primera supone la existencia actual de unos 200 países, frente a apenas 65 en el periodo entreguerras; la segunda, la interrelación de economías entre esos estados, relacionada a su vez con la revolución en el campo de las comunicaciones (información), de los mercados primarios (una operación en un segundo puede afectar a la economía y seguridad de muchos estados) e incluso del pensamiento (lo económico prima sobre lo político).

Otros condicionantes son el resurgimiento de la tensión Norte-Sur (desigualdades socio-económicas, desplazamientos humanos, frustración que conduce a la inestabilidad, al crimen y al terrorismo) o los problemas medioambientales.

Ante ese escenario, grosso modo expuesto, difícilmente una potencia puede por sí sola garantizar la estabilidad internacional del mundo.

Bien es cierto que Estados Unidos tiene hoy día un papel hegemónico, pero no se puede marginar la postura que adopta una Rusia en crisis, las grandes y medias potencias europeas, el papel regional de la República Popular China, el gigante económico Japón, y por supuesto el papel de las diversas organizaciones internacionales e incluso de las empresas multi o transnacionales, así como el de los grupos religiosos -en especial los de carácter fundamentalista-.

Para completar este amplio escenario con tal gama de jugadores, no nos queda sino añadir las «nuevas» amenazas y desafíos, que incluyen el 


\section{El poder aeroespacial ya es un hecho}

terrorismo internacional -hoy sin necesidad de apoyo de estados, y a veces incluso sin ideología- disperso en el mundo pero que, merced a las nuevas tecnologías, tiene posibilidad de conexión en cuanto a comunicaciones y económica, los integrismos y fanatismos, las violaciones de derechos humanos, las explosiones demográficas en África y Asia, la militarización del Tercer Mundo, el tráfico de estupefacientes ....

\section{Los acontecimientos del 11 de septiembre de 2001}

Los recientes ataques terroristas a Nueva York y Washington pueden hacer que se cuestionen proyectos de la envergadura del denominado Programa de Defensa de Misiles preconizado por el presidente norteamericano George Bush.

Podría cuestionarse también la Iniciativa OTAN sobre Capacidades de Defensa (ICD) de la cumbre de Washington de abril de 1999; iniciativa que supone inversión en tecnologías punta y capacidades consideradas esenciales, mejorando al mismo tiempo aspectos imprescindibles de interoperabilidad entre aliados y socios. Ello va a suponer cambios, como anunciaba el Secretario General de la OTAN el pasado año, Lord Robertson, que nos preparen para afrontar «un mañana impredecible» .

$\mathrm{Y}$, en consecuencia, cabría poner en tela de juicio a la denominada Identidad Europea de Seguridad y Defensa (IESD), que supone asimismo una mejora europea de sus capacidades, a fin de equilibrar, de un modo más justo, los respectivos papeles y responsabilidades (de Europa y EE.UU.).

Desafortunadamente, los citados acontecimientos no implican que deba prestarse toda la atención a posibles acciones de carácter terrorista, en detrimento de la atención necesaria dedicada a otras amenazas, o ataques de otro tipo, sean nucleares o convencionales.

Los sucesos del 11 de septiembre no hacen sino evidenciar las capacidades de actuación de una de las amenazas, y en consecuencia poner de manifiesto la necesidad de mejorar los mecanismos de seguridad.

Es decir, en el campo de la seguridad y la defensa, todo sigue igual que un día antes del atentado, pero además....

... Además hay que seguir trabajando en lo que se había iniciado, incluyendo naturalmente los cambios que se vayan estimando necesarios, y desbordando en imaginación al enemigo conocido o posible.

\section{El uso militar del espacio: una necesidad}

Para comprender el alcance de la ICD de la OTAN, y su consecuencia en Europa con el desarrollo de la IESD, quizá merezca la pena mencio- 


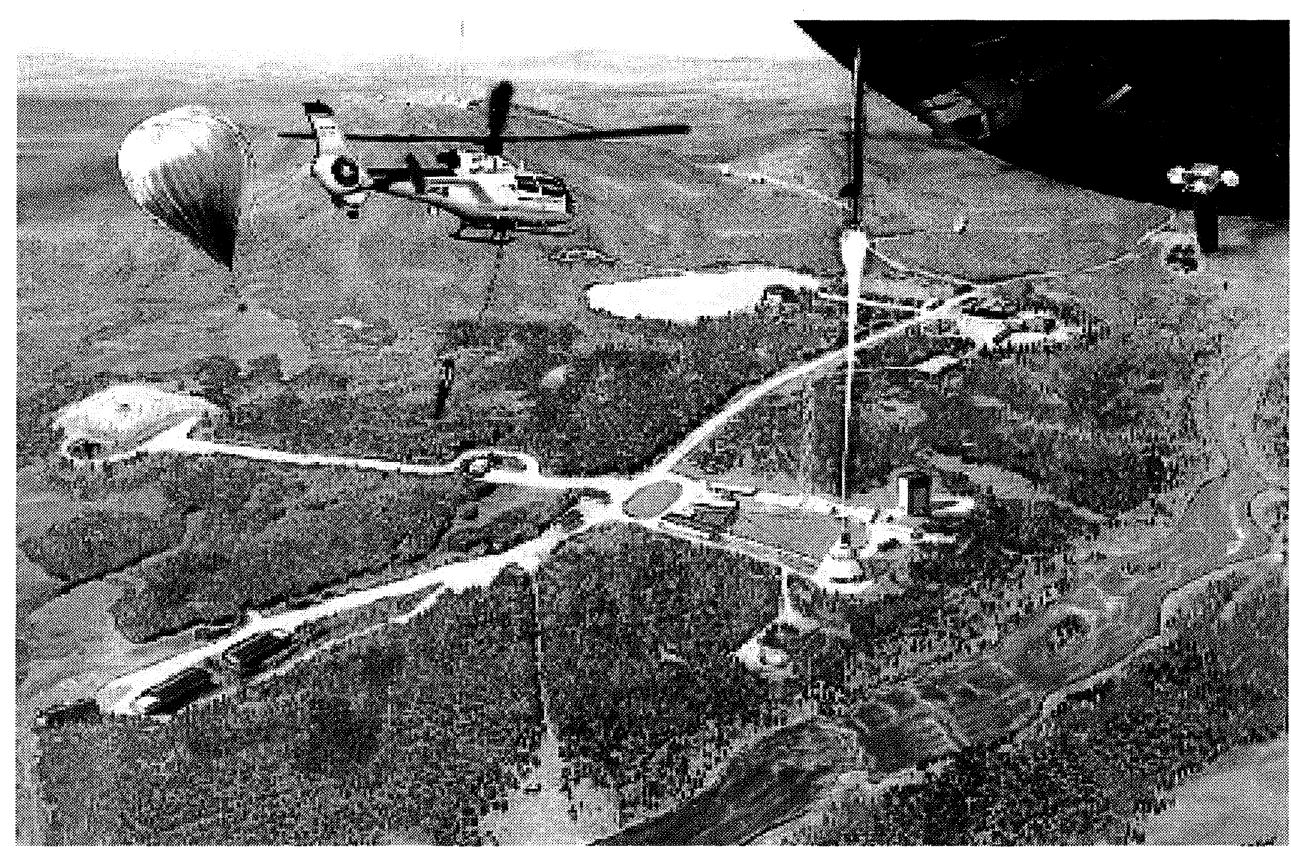

nar que la citada iniciativa se deriva de la denominada Revolución en Asuntos Militares iniciada hace unos años por Estados Unidos, y que supone un cambio fundamental en la conducción de la guerra ${ }^{1}$ mediante la aplicación de nuevas tecnologías: misiles guiados de precisión, sistemas de armas no detectables, sistemas de vigilancia y reconocimiento aéreos y espaciales, y sistemas avanzados de mando, control, comunicaciones e informática. Todo ello, naturalmente, incorporado a las nuevas doctrinas militares y conceptos operativos y organizativos.

A la vista del panorama internacional, era en cierto modo lógico que se planteara esa Revolución en Asuntos Militares; y una de sus consecuencias, la IESD, no es sino resultado de las limitaciones europeas puestas de manifiesto en la práctica, fundamentalmente en la operación «Allied Force» en Kosovo la primavera de 1999, donde, por ejemplo, apenas un $10 \%$ de los aviones europeos fueron capaces de efectuar bombardeos de precisión (eso sí, España entre ellos).

Así, entre los múltiples factores que dan lugar a esa revolución e iniciativas, cabe citar:

- Los avances en la tecnología militar (telecomunicaciones, informática, sensores). 
- La necesidad de compensar el déficit de efectivos humanos con mejoras cualitativas.

- El entorno estratégico, al que se han añadido amenazas y riesgos impredecibles, que requieren su avanzada detección y una rápida movilización.

- La amplia gama y dispersión de escenarios.

En este contexto, al vernos obligados a utilizar los últimos avances tecnológicos, y abarcar el mayor número de posibles escenarios, con múltiples tipos de amenazas, detectándolas lo antes posible, y disponiendo para todo ello de un limitado número de efectivos, no cabe sino pensar en la utilización militar del espacio «que todo lo engloba».

\section{El poder espacial}

La disimetría en cuanto a capacidades de que hablábamos al principio ha hecho que surjan, por decirlo así, concepciones distintas respecto al poder espacial.

Así , en Estados Unidos hay quien afirma que la Iniciativa de Defensa Estratégica ( «SDI»), de Ronald Reagan, y posteriormente las discusiones sobre la Revolución en Asuntos Militares han obstaculizado la interpretación del Poder Espacial. Dicha revolución se asoció en los ochenta a los misiles balísticos de defensa, y en los noventa a la provisión de información. Propugnan algunos que el espacio debe ser reconocido como un ambiente geográfico en el que se desarrolla el conflicto, no distinto, en el sentido estratégico, a la tierra, al mar o al aire.

Los defensores de esta idea se lamentan de que existen juicios políticos, legales, tecnológicos, incluso operacionales y tácticos que impiden una interpretación concreta del poder espacial.

Reconocen, sin embargo, que hoy día las capacidades de la guerra del espacio son modestas, pero que el hecho de que la era espacial (incluyendo el combate en el espacio, desde el espacio, por el espacio) no sea inminente, no significa que sea imposible.

Al definir el poder espacial como «la capacidad en paz, crisis y guerra de ejercer una influencia rápida y duradera en el espacio y desde el espacio», deben tenerse en cuenta la vulnerabilidad de las plataformas orbitales y de sus cargas útiles.. Por ello, es sin duda acertada la definición de control del espacio como «la capacidad de asegurar el acceso al espacio, la libertad de operaciones dentro del medio espacial, y la capacidad de negar a otros la utilización del espacio». Es decir, si no se puede asegurar y mantener el control del espacio, difícilmente se podrá explotar el 
espacio con confianza y negar esa explotación a otros. O sea, «si no eres capaz de controlar el espacio en la mayor de las batallas del próximo siglo, perderás».

Según se deriva de sus manifestaciones y primeras acciones, esta teoría es compartida por el responsable de Defensa estadounidense Donald $\mathrm{H}$. Rumsfeld, quien ha decidido colocar el espacio exterior entre sus grandes prioridades. Junto a la polémica del escudo antimisiles, el Secretario de Defensa se ha comprometido a potenciar esta «nueva frontera»: un general de cuatro estrellas de la Fuerza Aérea coordinaría las actividades del Departamento de Defensa relacionadas con el espacio, desde la detección de misiles balísticos al conjunto de satélites de observación, hasta ahora a cargo de la CIA. Esta decisión ha dado lugar a especulaciones sobre la posible creación de una fuerza del espacio, al margen de la tradicional estructura de Tierra, Mar y Aire.

Naturalmente, esta forma de pensamiento -y quizá de actuación- es fruto de la disimetría antes mencionada. No nos oponemos a ella en absoluto; de hecho defendemos toda postura avanzada e imaginativa. Sucede, sin embargo, que la disimetría es real; máxime si la aplicamos a nivel nacional. Es decir, las pretensiones deben ir acordes con las capacidades reales; eso sí, sin perder de vista la proyección futura.

Es evidente que en estos momentos Estados Unidos depende del espacio más que ningún otro país del mundo (desde predicciones meteorológicas a comunicaciones). En el caso concreto de las fuerzas armadas, su dependencia de sistemas espaciales en apoyo de sus funciones esenciales (comunicaciones, navegación, reconocimiento, meteorología, etc. ) es cada vez mayor; evidentemente, cualquier posible enemigo intentará impedir ese apoyo.

Huelga decir que nuestra situación a nivel nacional (a nivel europeo quizá sea más discutible) dista un abismo de parecerse a la estadounidense, sin embargo el camino por nosotros iniciado lleva análoga dirección.

\section{Un inciso}

Si bien hemos mencionado que Europa está tratando de acortar distancias con Estados Unidos, debemos, no obstante, ser realistas; al fin y al cabo, no es hasta el año 2000 cuando se plasma un documento sobre «Estrategia europea para el espacio», en el que se menciona la competencia tecnológica europea: el lanzador Ariane abarcando el 50\% de lanzamientos comerciales, el papel de la Agencia Espacial Europea (ESA),... y en defini- 
tiva, la apertura, con esta estrategia, de un nuevo capítulo en el acercamiento de Europa al espacio; cuya estrategia sería endosada por el Consejo de la Unión Europea, el Parlamento Europeo y el Consejo de la ESA.

Este componente estratégico espacial abarca sistemas de comunicaciones, sistemas satélite de navegación y posicionamiento, sistemas de observación por satélite, y estudio científico del espacio. Cabe destacar, particularmente, la decisión tomada acerca de un sistema global de navegación por satélite (GALILEO) análogo al GPS estadounidense - cuya estructura civil ha dado lugar a cuestiones de seguridad, que deberán ser tratadas durante la fase de validación -, o el denominado Control Global para Medio Ambiente y Seguridad (GMES), que pretende ser el vínculo entre los requerimientos políticos europeos y las capacidades proporcionadas por los satélites de observación.

Es decir, el camino europeo está abierto, pero Estados Unidos avanza imparable con objetivos mucho más concretos: así, el sistema SBIRS (Sistema de Infrarrojos basado en el Espacio) estará en funcionamiento a quince años vista, y el SBR (Radar Basado en el Espacio) poco después. El proyecto SBIRS consiste en una constelación de treinta satélites (4 en órbita geosíncrona, 24 en órbita baja y 2 en elíptica) para la detección avanzada de misiles y su seguimiento preciso; en cuanto al SBR, se trata de una constelación de 24 satélites radar para seguimiento en todo tiempo de blancos terrestres móviles, en cualquier zona del globo terrestre. Otro proyecto a veinte años vista sería el SOV (Vehículo para Operaciones Espaciales), capaz de transportar mini o microsatélites hasta posicionarlos en órbitas bajas, cuya operación podría llevar a cabo varias veces al día, y una de cuyas misiones sería depositar satélites maniobrables en órbita capaces de inutilizar la operación de satélites enemigos.

Como vemos, en el campo de la defensa y la seguridad, no hay duda acerca de la distinta forma de enfrentarse al futuro.

\section{Abundamiento en el control del espacio}

Por su importancia, y antes de seguir adelante, queremos hacer hincapié en este importantísimo aspecto. Es evidente que no se puede hablar de poder si no se mantiene la superioridad, y ésta no existe si no se dispone del control. Este aspecto es doctrinal, por lo evidente, y en consecuencia crucial para el planificador militar.

¿Y qué incluye ese control espacial que antes hemos definido?. Fundamentalmente vigilancia y reconocimiento, y operaciones en el entorno espacial. La primera supone la detección, identificación y seguimiento de 
los miles de objetos existentes en él, desde naves hasta basura espacial; el segundo englobaría operaciones con satélites, operaciones de transporte espacial, operaciones de contraespacio,...

No se puede ocultar la dificultad que entraña el control del espacio. Dicha dificultad suele plantearse más que como fruto de la complejidad, como consecuencia de su carestía. Claro que, en este campo lo caro y lo barato es tremendamente relativo, y siempre producto de voluntades políticas.

En cualquier caso, debe tenerse muy presente que jugar con el poder aeroespacial, y pretender ganar, sin contar con el control aeroespacial, es poco menos que arriesgar la victoria a cara o cruz; riesgo difícilmente asumible por cualquier líder militar o civil.

\section{El espacio. Elemento integrador}

Una vez familiarizados con el espacio, vista la necesidad de su utilización -en particular desde el punto de vista militar, que es el que nos ocupa- ¿cuál es nuestra postura respecto de la utilización del aire-espacio?.

A la vista de lo expuesto, y a fuer de pragmáticos, es claro que nuestra posición no debe identificarse exactamente con la norteamericana. Incluso para Estados Unidos, la era espacial (del combate en, desde y por el espacio) no está a la vuelta de la esquina. Se lo pueden plantear, desde luego, con mucha mayor justificación que cualquier otro país; pero hoy día, la realidad sigue siendo "aeroespacial».

Separar en estos momentos lo aéreo de lo espacial arguyendo que las operaciones aéreas y las del espacio difieren lo suficiente como para requerir organizaciones separadas, es muy poco realista. Claro que tampoco parece defendible el obcecarse en definir como contrarias al arte militar esas divisiones verticales.

Lo único claro es que la circunstancia es la que manda. Y la circunstancia actual viene reflejada por la actual experiencia.

Durante la guerra fría se superpusieron operaciones aéreas y espaciales, utilizando aviones de reconocimiento y satélites de observación, combinando sus resultados; o radares terrestres de alerta temprana balística (BMEW) y satélites, conjugándolos con aviones de defensa aérea en alerta permanente. Efectivamente, en esa época en Estados Unidos existía una estrecha relación entre la Oficina Nacional de Reconocimiento (NRO) y la Fuerza Aérea, o entre esta y la Agencia Central de Inteligencia (CIA) con sus satélites espía.

Sin embargo, es después de la guerra fría, con la Guerra del Golfo Pérsico en 1991, cuando se subraya la importancia de esa combinación 


\section{INTEGRACIÓN EN EL ENTORNO C4I}

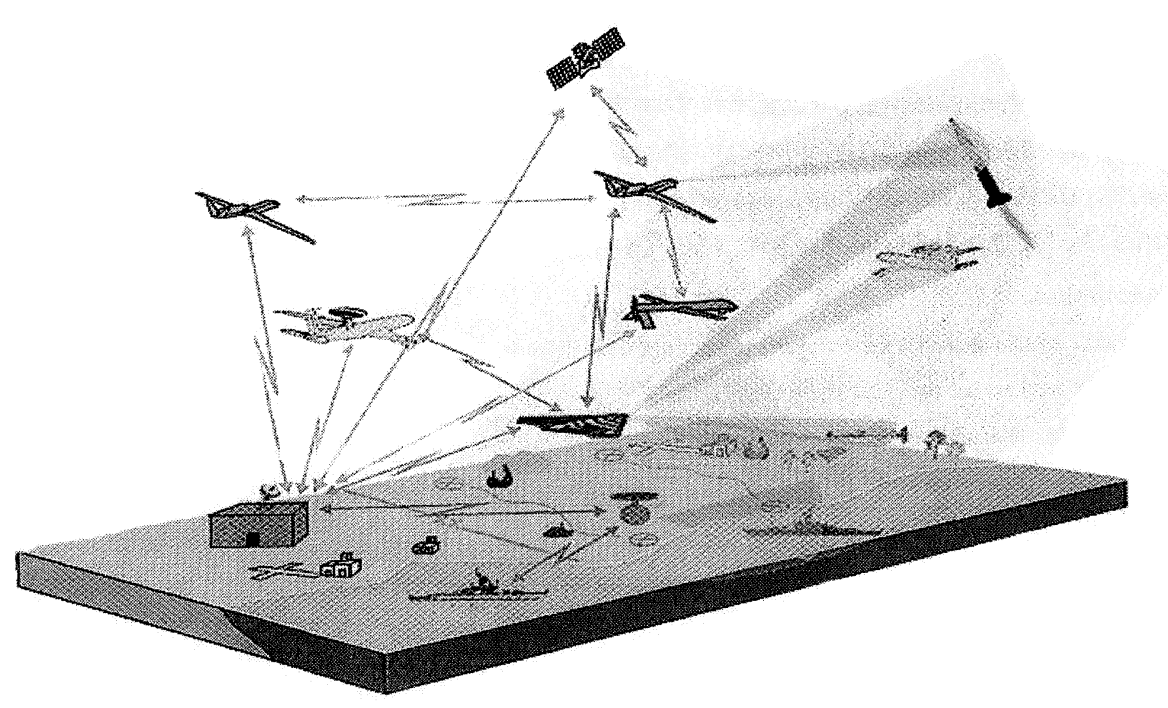

en la conducción de las operaciones militares. De hecho, a la operación «Tormenta del Desierto» se le considera «la primera guerra apoyada desde el espacio", reconociéndose que los recursos en el espacio tuvieron una influencia decisiva para llevar a cabo la campaña aérea que destruyó las capacidades militares iraquíes, así como que gracias a la observación de los movimientos y posiciones del enemigo, alerta temprana de misiles, comunicaciones y navegación vía satélite, los satélites se convirtieron en un nuevo brazo armado, y en cierto modo el ejército más importante.

En la última década, y con esa experiencia, la Fuerza Aérea estadounidense ha progresado considerablemente en la integración de sus operaciones aéreas y espaciales, y así quedó demostrado en la operación «Allied Force», y más recientemente se está reflejando en las operaciones que se están desarrollando en Afganistán («Libertad Duradera»).

Y si esto es así -repetimos, en el momento actual y en el más próximo futuro- para la primera potencia, en el caso español (y para el resto de países europeos) una concepción distinta sería poco menos que irresponsable. «Demos tiempo al tiempo».

Bien es cierto que, si necesaria es la integración aire-espacio, no lo es menos la integración mar-espacio y tierra-espacio. Es decir, el espacio se ha convertido en el medio integrador de los tres elementos clásicos. De este modo, formar parte de un sistema C4I (Mando, Control, Comunicaciones, 
Ordenadores e Información), significa integración en el aire-espacio; el mando y control se producirán, las más de las veces, a través de plataformas aéreas (convencionales o no tripuladas), de satélites, o de ambos a la vez.

Es decir, para nosotros el poder aeroespacial es un hecho. ¿Lo es el poder espacial? ¿Podemos en estos momentos garantizar el acceso de nuestras plataformas al espacio, llevar a cabo con libertad operaciones en el medio espacial, y negar a otros la utilización del espacio?

Naturalmente son cuestiones cuya respuesta afirmativa debemos perseguir, pero, hoy día, sin dejar de tender hacia esa meta, nuestro objetivo debe ser consolidar el poder aeroespacial propio.

\section{Consolidación del poder aeroespacial}

Somos conscientes de que la acción militar está subordinada a las consideraciones políticas, y de que los medios militares deben ser proporcionales a los objetivos políticos. Pues bien, hoy es precisamente el poder aeroespacial (no olvidemos que tecnología y poder aeroespacial son uña y carne) el que permite una correcta aplicación de esos principios, pues facilita -incluso físicamente- la proyección de la voluntad política con un alto nivel de eficiencia (eficacia al mínimo coste).

Sabido esto, sin embargo, en nuestro caso se adolece quizá de falta de precisión en el modo de afrontar esa realidad. Se tiene en cuenta, desde luego, pero sólo de forma indirecta. Cuando el ministro de Defensa comparece por primera vez ante el Parlamento el pasado junio-2000, y hace hincapié en la europeidad de España, o en sus intereses mediterráneos y atlánticos, o en su responsabilidad con la Comunidad Iberoamericana de Naciones, o en la necesidad de incrementar su capacidad para realizar misiones «Petersberg», o en cuanto a la labor española en misiones de verificación de acuerdos de desarme y control de armamentos, o en dedicar especial atención a programas que permitan actuar en tiempo real, en escenarios lejanos, con cualquier condición meteorológica, o en sistemas de inteligencia,..... uno no puede por menos que pensar en la utilización del medio aeroespacial., ¿De qué otra forma si no, se pueden abarcar tantos objetivos?. ¿Qué otro medio proporciona la globalidad necesaria en cuanto a vigilancia, reconocimiento, comunicaciones, localización de objetivos?

Es cierto que la situación de España en el marco europeo no es nada desdeñable en el campo aeroespacial. Aparte de los programas de comunicaciones desde el espacio, nos hemos involucrado en los satélites de observación Helios $1 \mathrm{~A}$ y $1 \mathrm{~B}$, y está en camino la firma de nuestra participación en Helios II. Nuestra capacidad real de observación a escala 
europea sólo es equiparada por Francia e Italia en estos momentos. El rendimiento operativo obtenido hasta hoy es muy satisfactorio, y se verá incrementado con la mejora de resoluciones que ofrece Helios II, aparte de añadir la capacidad infrarroja a las actuales prestaciones. Si a ello añadimos la posible participación en un futuro sistema global europeo, ahora en estudio, nuestra posición se iría afirmando.

Para ello, todos estas consideraciones, hoy a nivel «declaración de intenciones» por decirlo así, debieran ser tenidas en cuenta en el marco de una política espacial perfectamente definida. Esa definición se incluiría en las correspondientes directivas (Nacional y Militar) para dar lugar a una estrategia de empleo y consiguientes doctrinas, quizá mediante un plan director espacial.

El hecho de disponer de una política de acción, significa contar con un plan de acción a nivel administración para influir en las decisiones y actuaciones. Es decir, esa política nos señala «lo que hay que hacer».

La doctrina, por otro lado, como compendio de principios fundamentales de empleo persiguiendo la eficiencia, nos indica «cómo hay que hacerlo».

Definida esa doctrina podríamos organizar, entrenar, equipar y emplear los recursos de manera adecuada.

Quizá otra forma de proceder sería la confección de una doctrina espacial (al fin y al cabo se trata de recoger principios y formas de acción), que serviría de base para la definición de la estrategia y política espaciales. Preferiríamos el procedimiento inverso, como más lógico; pero dada la situación en que en estos momentos nos encontramos, la segunda opción puede ser válida, aunque se apoyaría en elementos de base escasamente definida. Téngase en cuenta que la legislación sobre el uso del espacio es limitada ${ }^{2}$, por lo que sería necesario contar con directrices lo más concretas posibles.

En cualquier caso, una vez planteada la doctrina espacial, se consideraría la confección de una doctrina aeroespacial - que, como ya hemos mencionado, parece lo doctrinalmente conveniente en estos momentos para cuyo desarrollo se tendrían en cuenta aspectos del espacio, como los citados en cuanto a globalidad: posibilidad de movimiento sin restricciones, capacidad de observación, cobertura, precisión (en cuanto a calidad de información), flexibilidad (en cuanto a funciones); cuyos aspectos habría que compatibilizar de forma adecuada con las conocidas características del poder aéreo: altitud, velocidad, alcance, flexibilidad (respecto del lugar, momento, objetivo), precisión y letalidad. Y, finalmente, para cerrar el círculo, bastaría recoger los requisitos fundamentales del poder aéreo y aplicarlos a los sistemas espaciales. Al fin y al cabo, no parece que exista duda alguna acerca de la racionalidad de dicho engrana- 
je: interoperabilidad (de sistemas, unidades y fuerzas), mantenimiento de las operaciones en el tiempo, supervivencia, capacidad operativa todo tiempo, disponibilidad operativa, formación/entrenamiento y comunicaciones, son requisitos que necesitan escasa explicación para ser aplicables a los sistemas espaciales.

En suma, disponemos de lo que tenemos, pero es preciso afianzarlo; mirando hacia el futuro, ciertamente, pero con solidez y racionalidad.

No olvidemos que cualquier inicio es duro; basta recordar el escepticismo con que se miraba a la aviación a principios del siglo XX. Sin embargo, hoy, ningún ejército puede prescindir del arma aérea, del poder aéreo. El próximo paso es claro: la consolidación del poder aeroespacial.

\section{Conclusión}

A nadie se le escapa que el espacio ha perdido en los últimos años su carácter exclusivamente militar, si bien esta afirmación no debe hacernos perder de vista dicho aspecto, que crece en importancia a medida que aumenta la importancia civil cuyos intereses es preciso defender. El peso de la realidad se acaba siempre imponiendo; de ahí que desde el inicio de este artículo hemos insistido en lo real, lo pragmático. Y por ese mismo motivo defendemos la idea de que hoy día el poder aeroespacial es uno de los factores base para la seguridad y para la defensa de nuestros intereses político-económicos.

A escala europea, conviene concretar y definir las necesidades comunes a los países de la Unión Europea a medio y largo plazo, en todos los aspectos del conjunto espacial: observación de la Tierra, telecomunicaciones, navegación, señales, vigilancia del espacio y alerta antimisil, incidiendo en los aspectos de control espacial.

A escala nacional, y siempre dentro de ese entorno de cooperación que tan bien se ha iniciado, debe fijarse el modo de consolidación del poder aeroespacial, para lo cual es preciso cubrir planos de política de acción y doctrinales. Experiencia, la hay; y la operación «Libertad Duradera» no hace sino afianzar nuestra idea: el poder aeroespacial es un hecho, y el control espacial una necesidad ${ }^{3}$.

\section{Notas}

1 Curiosamente, el Mando Espacial de EE.UU. (USSPACECOM) enuncia que la Revolución en Asuntos Militares supone «un cambio en la naturaleza de la guerra». Noso- 


\section{El poder aeroespacial ya es un hecho}

tros somos partidarios de lo permanente en cuanto a su naturaleza, cualquiera que sea el entorno o la tecnología empleada, y preferimos hablar de «un cambio en cuanto a la conducción de la guerra".

2 Tratado de proliferación de pruebas nucleares de 1963, Tratado del espacio exterior de 1967, Acuerdo de rescate y retorno de astronautas y recuperación de objetos del espacio exterior de 1968, Convención internacional sobre riesgo de daños causados por objetos espaciales de 1972, Tratado de Misiles antibalísticos de 1972, Registro de objetos lanzados al espacio exterior de 1975, Tratado de limitación de Armas ofensivas de 1979, Tratado de la luna de 1979

$3 \mathrm{El}$ modo en que el Departamento de Defensa estadounidense ha bloqueado el acceso a las imágenes de alta resolución IKONOS, no es sino una forma de control espacial. Se demuestra asimismo la conveniencia de disponer de autonomía en este campo.

\section{Bibliografía}

BARRY, JOHN L., Mayor general USAF - «Integración del Aeroespacio». Revista AEROSPACE POWER, $4^{\circ}$ trimestre 2000.

Cano, Ricardo. Cte. Ejército del Aire. «Uso militar del espacio». Monografía de Estado Mayor, 31 marzo 2000/ Boletín CESEDEN núm. 265, año 2000.

Grecia. Estado Mayor de la Fuerza Aérea Griega. Div. De Operaciones. Atenas, nov. 2000. "El desarrollo de una Doctrina Espacial Básica».

Herriges, DARREL L., Coronel USAF .- “Integración del Aeroespacio», Revista AEROESPACE POWER, $4^{\circ}$ trimestre 2000.

Pereira Castañares, JuAN C. .- «El debate sobre la nueva arquitectura europea de cooperación y seguridad». X Jornadas Universidad Complutense de Madrid- CESEDEN. Monografías del Centro Superior de la Defensa Nacional, núm. 38. Agosto 2000.

ROBERTSON, LORD. Secretario General de la OTAN .- «Una Alianza equilibrada y más capaz». Revista de la OTAN. Primavera-verano 2000.

Rodríguez, Pedro. "Las claves de la Nueva Política de Seguridad estadounidense». $R E$ VISTA ESPAÑOLA DE DEFENSA, núm. 160. Junio 2001.

SchathöFeR, G.L.K., Col. F.A. Alemana. «El empleo militar del espacio». Cátedra Alfredo Kindelán, 27 nov. 2000.

SlOAN, ElinOR. «La DCI: Una respuesta a la Revolución en Asuntos Militares». Revista de la OTAN. Primavera - verano 2000.

Tamame Camarero, José. Col. Ejército del Aire. ««Satélites militares de observación: situación actual y perspectivas». Jornadas El Espacio y la Defensa Nacional. Círculo de Tecnologías para la Defensa. Octubre 2000.

Teste, Tcol. Fuerza Aérea Francesa. «From Air Power to Aeroespace Power». Seminario Escuela de Guerra Ejército del Aire. 27 nov. 2000.

Trillo-Figueroa, Federico. Ministro de Defensa. Primera Comparecencia Parlamentaria del Ministro de Defensa Excmo. Sr. D. Federico Trillo-Figueroa y Martínez-Conde. Ministro de Defensa. Agosto 2000.

Tyson, Dustin. Lt. Col. USAF. «From Air and Space to Aerospace». Cátedra Alfredo Kindelán. 28 nov. 2000.

Unión Europea. «Joint ESA/EC Document on European Strategy for Space, Annex II».

VALDERRÁbano LóPez, ANTONio. Col Ejército del Aire. «Consideraciones sobre doctrina espacial». Cátedra Kindelán. Noviembre 2000. 